\title{
SCIENCE AS RADICAL KNOWLEDGE
}

\section{LA CIENCIA COMO CONOCIMIENTO RADICAL}

\author{
Gonzalo Munévar \\ University of California, \\ Berkeley - United States of America. \\ Recibido diciembre de 2017/Received December, 2017 \\ Aceptado marzo de 2018/Accepted March, 2018
}

\begin{abstract}
RESUMEN
La visión de que la ciencia es típicamente un proceso acumulativo y progresivo, como lo sugieren algunos historiadores de la ciencia y algunos realistas científicos, está minada tanto por la historia como por consideraciones evolutivas sobre la naturaleza de la ciencia. Los intentos de utilizar la biología evolutiva para retratar el desarrollo científico como continuo se basan en desafortunadas analogías con la evolución de la vida. Una aplicación adecuada de la biología evolutiva, en combinación con la neurociencia, derrota el caso del realismo en cuestión y conduce a la comprensión de que la ciencia no solo está abierta a la transformación radical, como lo indica la historia, sino que debería ser así. Los enfoques no evolutivos para la continuidad histórica de la ciencia, como el de Lakatos, no tienen mejor suerte. Como discutiré, la ciencia es una forma radical de conocimiento.

Palabras Clave: Feyerabend, Galileo, Lakatos, Epistemología Evolutiva, Realismo, Relativismo Evolutivo, Proliferación de Teorías, Verdad Relativa.
\end{abstract}

\begin{abstract}
The view that science is typically a cumulative, progressive process, as suggested by some historians of science and some scientific realists, is undermined both by history and by evolutionary considerations about the nature of science. The attempts to use evolutionary biology to portray scientific development as continuous are based on unfortunate analogies to the evolution of life. A proper application of evolutionary biology, in combination with neuroscience, defeats the case for the realism in question and leads to the realization that science is not only open to radical transformation, as history indicates, but that it should be so. Non-evolutionary approaches for the historical continuity of science, such as Lakatos', do not fare much better. As I will argue, science is a radical form of knowledge.

Key Words: Feyerabend, Galileo, Lakatos, Evolutionary Epistemology, Realism, Evolutionary Relativism, Proliferation of Theories, Relative Truth.
\end{abstract}

\section{Introduction.}

The history of science undermines the famous historian of science George Sarton's view to the effect that "the acquisition and systematization of positive knowledge are the only human activities which are truly cumulative and progressive" (Sarton, 1936). To show this, in the first part of this paper, I will mainly appeal to Galileo's own account of his key argument in favor of the motion of the Earth. And in the second part of the paper I will call attention to how considering the nature of mind and science in the context of evolutionary biology further undermines not only this view but also a version of scientific realism itself that attempts to buttress it.

* Autor correspondiente / Correspondig author: gmunevar@1tu.edu 
History.

The view that the Earth moves may seem commonsensical to most of us today. But that is only because we are heirs to a revolution in scientific thought. When the battle was fought, victory was by no means easy. Among the many telling objections against the movement of the Earth, perhaps the Tower Argument, presented by Aristotle (año edición utilizada) almost 2,000 years earlier, was the strongest of all. In a modern version, it goes as follows. Suppose that you let go of a stone from the top of a tall tower. If the world moves, by the time the stone hits the ground, the tower, being stuck in the Earth, will have moved considerably. Thus, there will be a perceptible difference between the initial and final distances from stone to tower. But when we actually look, there is no difference at all! We plainly see the stone fall straight down. For the distance to remain constant, if the earth did move, the stone would have to fall in a parabolic path, but we can plainly see that it does not. Therefore, it is a plain fact that the Earth does not move.

It does no good to talk about gravity and the like, for the appropriate concepts were not developed until years later, and then partly as a result of Galileo's success. Presented with the Tower Argument, what could Galileo say? First, in "The Second Day" of his Dialogues Concerning the Two Chief World Systems, he made the argument against his own view as strong as possible (Galileo, 2001). For example, equal cannons shooting east and west will send their cannonballs pretty much the same distance, but if the Earth moved, the cannon shooting East should go a lot further. If you shoot a cannon straight up, and the Earth moves, by the time the cannonball falls to the ground, the cannon should have moved a great distance and the cannonball will hit the ground far from it; but obviously that is not so: The cannonball will fall back straight down towards the cannon. Galileo then acknowledges that all the experiments are on Aristotle's side! This greatly pleases Simplicio, Aristotle's representative in the dialogue, who admiringly tells Salviati, Galileo's representative, that it would appear to be "an impossible feat to contradict such palpable experiences." If these experiments were false, Simplicio asks, "(...) what true demonstrations were ever more elegant?" (Galileo, 2001, p. 155).
According to Newton's Third Law for Reasoning in Philosophy (science), the qualities of bodies determined by experiment ought to be considered universal, therefore the good (natural) philosopher does not entertain alternative accounts of the phenomena: "We are certainly not to relinquish the evidence of experiments for the sake of dreams and vain fictions of our own devising" (Newton, 1989, p. 146).

Nevertheless, Galileo does entertain hypotheses contrary to such powerful experimental results (contrary to Rule III) and does so without having produced any "other phenomena" (as Rule IV requires), i.e. no new observations or experimental results. What did Galileo do instead? He offered a theoretical argument. He begins by asking what may seem to be a silly question: How do we know that the rock falls vertically? We see it, obviously, as Simplicio points out ("by means of the senses"). But what if the Earth did rotate? How would the rock move then? Galileo's move here anticipates Feyerabend's advice to imagine "a dream-world in order to discover the features of the world we think we inhabit" (Feyerabend, 1975, p. 32). The Aristotelian Simplicio gives the answer: The rock would move with a compound of two motions, "one with which it measures the tower, and the other with which it follows it" (Galileo, 2001, p. 162). The real motion would thus be a compound of a vertical and a circular motion. Of course, this is implied: we only observe the vertical motion, since we share, with the rock and the tower, the motion of the Earth. A few pages earlier Galileo had pointed out that any motions that may be attributed to the Earth "must necessarily remain imperceptible to us... for as inhabitants of the earth, we consequently participate in the same motions" (Galileo, 2001, p. 132).

It follows, then, that from seeing the motion of the stone "you could not say for sure that it described a straight and perpendicular line, unless you first assumed the earth to stand still [emphasis added]" (Galileo, 2001, p. 162). But whether the Earth stands still is precisely what is in question. The evidence adduced to show that the earth stands still assumes that the earth stands still! Aristotle, the great logician, has committed the fallacy of petitio principii. His "facts" assumed the theory in question.

In a few pages, then, and without providing one single piece of new empirical evidence, Galileo 
disposes of the main objection against the very possibility that the Earth rotates, thus creating the stage for the eventual triumph of the Copernican Revolution. By relinquishing the evidence of experiments for the sake of a dream of his own devising, he was able not only to discover important features of the world we thought we inhabited, but eventually to show that such a world was itself a dream.

Galileo could say, and did, that the stone does not fall straight down, plain as it may be. The stone only seems to move so, for its real motion is far more complicated than that. But this makes no sense, people thought. Motion is observed motion. Not so, said Galileo. Shared motion goes unobserved (motion is relative). He made the point in the following dialogue:

Salviati: (...) imagine yourself in a boat with your eyes fixed on a point of the sail yard. Do you think that because the boat is moving along briskly, you will have to move your eyes in order to keep your vision always on that point of the sail yard and follow its motion?

Simplicio: I am sure that I should not need to make any change at all; not just as to my vision, but if I had aimed a musket I should never have to move it a hairsbreadth to keep it aimed, no matter how the boat moved.

Salviati: And this comes about because the motion which the ship confers upon the sail yard, it confers also upon you and upon your eyes, so that you need not move them a bit in order to gaze at the top of the sail yard, which consequently appears motionless to you. (And the rays of vision go from the eye to the sail yard just as if a cord were tied between the two ends of the boat. Now a hundred cords are tied at different fixed points, each of which keeps its place whether the ship moves or remains still). (Galileo, 2001, pp. 289-290).

The reason why the stone falls at that distance from the tower is that, as we have seen, its real motion has two components: The first is straight down and we notice it. The second (circular inertia) is shared with the Earth, the tower, and the observer (us); that is why we do not notice it, but it is there all the same. Just as the tower moved laterally, so did the stone. When we are in an airplane flying smoothly we do not perceive that the passenger sitting next to us and the magazine on our lap are traveling at 550 miles an hour, even if we know they both are. We do perceive the motion of the flight attendant up and down the aisle, and of the drink spilling on the sleepy man to our left. We perceive those motions that we do not share, but fail to notice those that we do. In this manner Galileo neutralized the objection against the Copernican view.

What conclusions can we draw about the Tower Argument then? According to Feyerabend, people noticed a phenomenon and interpreted it in what they thought was the most natural way, i.e., the stone moves only straight down. It was this natural interpretation of the phenomenon, not the phenomenon itself, which contradicted the Copernican view. Galileo did away with the contradiction by providing a different set of interpretations (Feyerabend, 1975). Galileo, then, constructed a new empirical basis! This new empirical basis, furthermore, is constituted by a new theory of interpretation. In other words, when confronting facts that refuted his theory, Galileo changed the facts!

On the surface, we had a clash between theory and fact, for clearly that the stone falls straight down looked like a fact if anything did. What we did really have was a clash between a rather explicit theory (i.e., Copernicus) and a covert theory of interpretation. After close analysis, it turns out that instead of theory vs. fact, we have theory vs. theory. In any event, the main moral of the story is that observations make theoretical assumptions, and thus it is arbitrary to go along always with the judgment of experience, no matter how careful, inter-subjective, and so on (again, all those requirements were met in the case of the Tower Argument).

It does no good to realism or empiricism to claim that since the "facts" were replaced then they could not have been real facts. In the first place, we have no way to tell the real ones from good imitations. That the stone falls straight down looked like a real one. In the second place, what brought Galileo the real facts, if we can grant for the sake of argument that there are real facts, was not more careful observation, or a purer experience, or anything of the sort. What permitted the change of empirical basis was a change in theoretical assumptions. Apart from assuming that the Earth could move, Galileo changed the 
concept of motion. Motion had been supposed by his opponents, the Aristotelians, to be only observable motion, i.e., it involved observable change of position over time. In the jargon of analytic philosophy of science, we might say that the Aristotelians had an operationalist concept of motion (i.e., that a phenomenon would count as motion only if it could be expressed in terms of observable changes). But Galileo introduced into the concept of motion components that could not be observed in principle, since shared motion was not observable for him. And in the particular case of the Tower Argument, one of those components was circular inertia, which the observer shared with the tower and the Earth.

Nor do we help realism or empiricism by suspecting that there is something terribly peculiar, unrepresentative about the case of the Tower Argument. For the thesis of the distinction of fact and theory can admit of no exceptions. And this case shows not only that what looked like solid observations (and thus empirical "facts") are embedded in theory, but it also gives us an actual example. As long as it is possible to overthrow the judgment of experience, a theory is never proven to be false. There is no disproof in science any more than there is proof.

The Copernican Revolution is not the only example at our disposal. The history of science offers many other instances in which theoretical breakthroughs make short work of the most careful of observations, i.e. presumably solid facts are shown to be an illusion. According to Prout's hypothesis (circa 1815), atomic weights should be whole numbers (since they are multiples of 1 , the atomic weight of hydrogen). But the most refined techniques of the century showed unequivocally that the atomic weights of some substances were not whole numbers--chlorine was close to 35.5 , for example. With the advent of Bohr's quantum theory, a century later, we learned that the atomic weights of elements are determined by the total weights of protons and neutrons in the nucleus of the atom. The number of neutrons in an element may vary, however. Thus, different variations of the same element, named isotopes, will have different weights. In the case of chlorine, the two most stable isotopes will weigh respectively 35 and 37 (which, given their mix in nature, will result in a reading of 35.45 if the standard 19th century techniques are applied). Here we have one more case in which a theory, Prout's, clashed with the facts, for surely the careful observations in question were as "factual" as any observations had a right to be. Nevertheless, theoretical developments gave us a new way to interpret the troublesome observations and Prout's hypothesis was rehabilitated. The atomic weight of chlorine is a whole number. Different isotopes of chlorine will have different whole numbers as atomic weights. In this case the new theory of interpretation came from a different field - an esoteric branch of physics some hundred years after the birth of Prout's hypothesis. But once this view was taken up in chemistry, the entrenched observations were replaced by others in agreement with the new theory. Once more, theory overturns the negative verdict handed down by experience.

Returning to the Tower Argument, it is perhaps ironic that the Aristotelians, the losers, are now seen as sticking to the facts, demanding operationalist concepts, and on the whole defending empiricist method. What can we say now of the philosopher's praise of Galileo for preferring his eyes to his Aristotle? The important lesson for the purposes of this paper is that there may be, and indeed there have been, radical breaks - both in theory and fact - between a generally accepted view and the view that replaced it. Moreover, given the success of the approach taken by Galileo and many others, it is not only permissible but also advisable for science to encourage challenges to the dominant approach at any one time, no matter the degree of certainty felt by the consensus of scientists at the time (which was Feyerabend's point in Against Method). This clearly translates into a history of science that may on occasion radically deviate from continuous development.

Lakatos might be thought to come to the rescue of the continuity thesis when he acknowledges that progress requires competition but only within a scheme that requires that a successful competitor explain the unrefuted content of the view it replaces (Lakatos, 1970a, p. 118; Lakatos, 1970b, p. 100). But if the new view explains that content, that content is thereby preserved. The history of science should then be a sequence of additions to the content of previous views, and thus it should exhibit a reasonable amount of continuity: Its growth should be gradual. Nevertheless, how are scientists to judge what is the "unrefuted content" of the previous view? Surely not by the standards of the previous view. It will be the standards of 
the new view that determine what is acceptable and what not. For Lakatos "unrefuted" means "preserved in the new view" (Lakatos, 1970a, p. 137; Lakatos, 1970b, p. 101). Therefore, this requirement amounts to the vacuous demand that you preserve what you preserve, a demand unlikely to guarantee the gradual growth of science. This aspect of Lakatos' philosophy may seem like a minor inconsistency, however, once a more careful look at his position shows us that the new scientific view may overthrow any part of the previous view, or all of it. Indeed, his account of the history of Prout's hypothesis not only agrees with mine but endorses Soddy's sarcastic appraisal of the hard-won results of the distinguished galaxy of 19th Century chemists; results that appear (in the 20th) "as of little interest and significance as the determination of the average weight of a collection of bottles, some of them full and some of them more or less empty" (Lakatos, 1970a, p. 140). Furthermore, in agreement with Feyerabend's case for the proliferation of alternatives in Against Method, Lakatos tells us that:

in many cases the challenged observational theory, far from being well corroborated itself, is in fact an inarticulate, naive, 'hidden' assumption; it is only the challenge which reveals the existence of this hidden assumption, and brings about its articulation, testing, and downfall. (Lakatos, 1970a, p. 101).

If anything, Lakatos, then, provides reasons for a mechanism in science that is likely to undermine continuity.

\section{Evolution.}

The "evolutionary epistemology" developed by Popper (1972, pp. 239-40), Toulmin (1972) and others has tried to show that the history of science parallels the neo-Darwinian evolution of species (Hahlweg \& Hooker, 1989). Populations of scientific ideas, say, change as a reaction to pressures from the intellectual environment (an analogy to the process of natural selection). The motivation was that somehow such a parallel would lay bare the rationality of science by explaining how science has developed. And the consequence for the purposes of this paper is that, just as the evolution of species is gradual, so is the history of science.
As I have argued elsewhere (Munevar, 1981, 1989, 1998) and develop much further in a book in preparation (Munevar, 2018), evolutionary epistemologists tend to use the prestige of neo-Darwinism to get a seat at the table. But once they have made a few plausible comparisons, they announce that biological evolution is just the subset of a much more comprehensive theory of evolution - a theory that also includes cultural evolution, in which, e.g., the ideas acquired by one generation are passed on to the next. Described in neo-Darwinian terms, this extended theory includes the coupling of variation and selection and the inheritance of acquired characteristics. The evolutionary epistemologists, thus, sneak back in the very notions that neo-Darwinism had to discard in order to earn the prestige they borrow to get a seat at the table to begin with.

Even more troubling, however, is the very rationale for the enterprise. In trying to exhibit the rationality of science, the evolutionary epistemologists present their analogies to show that the development of science closely parallels the evolution of species according to neo-Darwinism. But even if such analogies were airtight, their conclusion would not be plausible. The evolution of life is not rational. Being like the evolution of life could not then make the evolution of science rational. The parallel could not suffice.

Human beings are part of nature and, when analyzing their conceptions of themselves and the world, we should indeed take into account the lessons that Darwin began to teach us in 1859 with the publication of his Origin of Species. In this vein, it pays to recall that science is a product of intelligence, that intelligence is an instrument of adaptation and itself the result of evolution. Now, as Piaget tells us, what distinguishes intelligence from other chemical and neural mechanisms of interaction with the world is that intelligence transcends the ability to respond to the immediate demands of the environment (Piaget, 1969). It is this freedom of response that permits intelligence to form sweeping views of the world and the means to criticize them. It seems to me that science is, of course, a communal enterprise that involves division of labor and is carried out in a social milieu. Science is thus, to speak perhaps metaphorically, but not inaccurately, a social application of intelligence to understand our world, a world of which we ourselves are part. 
Since science is human behavior, it should then be seen as part of the human phenotype, as other behavior is. This would allow to put our problem in perspective. Let us examine the example of organisms as simple as bacteria. In impoverished environments, one kind of bacteria will prey on their competitors. If their environment were to become rich in nutrients, the bacteria would change their behavior radically: They would avoid their competitors instead. We can explain their behavior by reference to their internal organization, their past history, and so on. But this explanation must not be limited to an account of the two phenotypic states, of the history of the behavior itself. The second behavior does not "follow" from the first in a logical or rational way. The organism simply undergoes a radical change of posture toward the environment. The explanation of the change of behavior on depends on our knowledge of the nature of the organism and the character of its interaction with the environment. The same kind of considerations should be paramount in the case of human science.

In a similar fashion, the content of our science at a certain stage need not be continuous with that which succeeds it (although in many actual cases there could be quite a bit of continuity). For under radical pressures or the excitement of truly radical new ideas, science may switch just as radically from one point of view to another as the bacteria's behavior does. The rationality of science should not depend, then, on the logical, theoretical, or empirical continuity of its content. To explain scientific knowledge, we may look instead at the mechanisms that bring about science and in the function that they allow it to perform.

There are two particular intuitions that afflict many philosophers. The first is that realism must be right - even if they cannot prove it. The second intuition is that relativism must be wrong- and they think they can easily show this. I will argue that these intuitions are misguided.

Scientific Realism is the view that the world has a certain structure, and that it is the function of science to try to find that structure. One important version of scientific realism holds that this view is supported by the success of science, because, as Richard Boyd says, truth is the only reasonable explanation of that success (Boyd, 1992). In this he follows Hilary Putnam, who argued in 1975 that realism "is the only philosophy that doesn't make the success of science a miracle" (Putnam, 1975, p. 79). Such a position has been elaborated from then until the present by a variety of authors including, in addition to Boyd (1989), J. Brown (1982), P. Lipton (1994), S. Psillos (1999), E.C. Barnes (2002), T. D. Lyons (2003), J. Busch (2008), G. Frost-Arnold (2010), and F. Dellsén (2016).

By contrast, Evolutionary Relativism holds that an organism's view of the world depends on its mind, that mind depends on biology, that biology supports a logically impeccable form of relativism, and that success explains truth, not the other way around (Munevar, 1998, 2018). This approach is consistent with the history of science and with present day science relevant to the pursuit of knowledge.

"Naive realism" has been challenged for a long time. According to Galileo, for example,

(...) tastes, odors, colors, etc., so far as their objective evidence is concerned, are nothing but mere names for something which resides exclusively in our sensitive body (...) so that if the perceiving creatures were removed, all of these qualities would be annihilated and abolished from existence. (Galileo, 1989, pp. 56-57).

What may surprise some is that Galileo's attitude, albeit with an evolutionary turn, is quite common today among scientists whose work must take perception into account. As the neuroscientist V. S. Johnston tells us, we must abandon the common-sense view of reality, because:

(...) although the external environment is teeming with electromagnetic radiation and air pressure waves, without consciousness it is both totally black and utterly silent. Conscious experiences, such as our sensations and feelings, are nothing more than evolved illusions generated within biological brains. (Johnston, 1999, p. 27).

Consider an example: The color spectrum is linear; our experience of the spectrum is not. Perceptually, red and green are "opposing" colors, but the wavelength difference between them is barely $1 / 150,000,000,000 \mathrm{~m}$. Why do we perceive such an extraordinarily small difference then? Evolution gives us the reason: Green "corresponds" to a band of frequencies reflected in normal white 
light by chlorophyll molecules, whose detection would have given an evolutionary advantage to our remote ancestors. Perception of other colors such as red and blue helps fix the detection of chlorophyll at dawn and dusk and in cloudy days. In a different place where vital resources depend on different chemical compounds, evolution may bring about a different perceptual parceling of the color spectrum. This means that the "normal" color experiences of creatures on Earth and on Carnap II (a yet to be discovered planet in Andromeda) may be quite different, even at the hypothetical level of the "sense data" so beloved by the logical positivists.

Moreover, perception often works through exaggeration. Small differences in "the world" are perceived as drastic differences in kind. In the brain, attention enhances a novel signal, not only by increasing the contrast with others but by making it stronger through dopamine secretion. Space science employs an equivalent process of radical, false contrast ("false color") to achieve success in its observation of other worlds, and of our own planet. Suppose that two minerals have very similar shades of brown. The picture taken by the spaceship is filtered through a computer that assigns very different colors to them, say purple to one and gold to the other. When looking at the false color picture we can now see the distribution of the two minerals on the surface of the planet. See Figure 1, in which false color allows us to see the tectonic patterns in the middle of the Atlantic Ocean. Perception works similarly: without exaggeration and contrast it would be very difficult to make the distinctions we need to make (and to make quickly oftentimes) in order to survive.

In addition, as Feyerabend points out, abstraction is necessary for perception to take place at all, else we would be awash in stimulation (Feyerabend, 1999). This construction by the brain is more than a bet on what is most likely to be in front of us. Indeed, the brain takes the direct response of its own neurons to sensory input and transforms it into a meaningful perception that is in important respects different from that response. As Edelman and Tononi (2000) point out:

(...) the activity of many neurons in sensory (...) pathways can be correlated with rapidly varying details of a sensory input (...) but do not seem to map to conscious experience.
For example, patterns of neural activity in the retina and other early visual structures are in constant flux [emphasis added] and correspond more or less faithfully to spatial and temporal details of the rapidly changing visual input. However, a conscious visual scene is considerably more stable [emphasis added], and it deals with properties of objects that are invariant [emphasis added] under changes in position or illumination, properties that are easily recognized and manipulated. (Edelman \& Tononi, 2000).

It seems, then, that abstraction, useful contrast, and exaggeration are the keys to perceptual success, not faithful resemblance.

The disconnect between "absolute truth" and success is also present in science at the level of theory. Greek astronomy postulated a universe with two basic spheres: The Earth in the center and the sphere of stars on the outer edge. This model has been an excellent guide to navigation. Only in the last century did modern science surpass it (with the help of electronic inventions, e.g. satellites that indicate position, etc.). That is, during more than two thousand years a completely false point of view has had great success in an area of great importance to the survival and welfare of human beings.

Figure 1. False color photograph exhibiting tectonic features of the Atlantic Ocean. Courtesy of NASA.

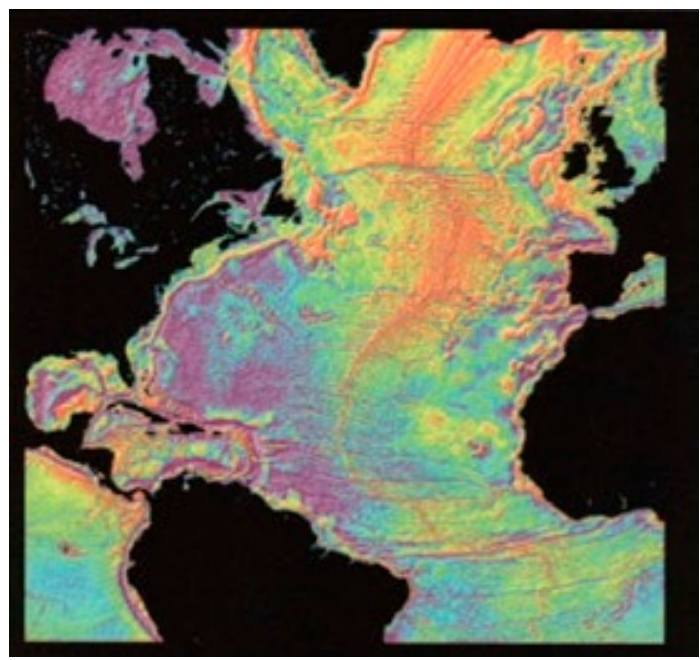

Boyd's claim that only realism can explain the success of science seems less than compelling. 
The most successful scientific field for the last century, and in the entire history of science, has been quantum physics, which in its orthodox interpretation is decidedly anti-realist. Niels Bohr expressed the point thus: “(...) an independent reality in the ordinary physical sense can neither be ascribed to the phenomena nor to the agencies of observation" (1987, p. 54). By "phenomena" Bohr does not mean the sense data of philosophers but the measured subatomic objects. Phenomena are always the result of specific interactions with specific measuring equipment; but we should not thus conclude that they are two separate things, one of which gives us information about the other, for Bohr insists in the "impossibility of any sharp separation between the behavior of atomic objects and the interaction with the measuring instruments which serve to define the conditions under which the phenomena appear" (Bohr, 1982, p. 210).

In some experimental arrangements an electron will behave as a wave, in others as a particle, but never as both. It all depends on what kind of measuring equipment we employ, and thus we end up with complementary descriptions. Real things, however, cannot behave as they appear to in double-slit experiments, according to the realists: We want to know the way the electron really is. These complementary descriptions, however, also cover the gamut of Heisenberg's uncertainty relations. One experimental arrangement allows us to measure the momentum of a particle but it brings about an uncertainty in its position, and so on. Given all of these considerations it seems unjustified to ascribe an independent reality to those subatomic objects. Furthermore, insisting on their independent reality requires doing away with the complementary of arrangements (and therefore of descriptions) that is inconsistent with that reality. But then we rule out discovering important aspects of the subatomic "realm." As Bohr puts it,

In fact, it is only mutually exclusive of two experimental procedures, permitting the unambiguous definition of complementary physical quantities, which provides room for new physical laws, the coexistence of what might at first sight appear irreconcilable with the basic principles of science. (Bohr, 1970, p. 139).
Bohr made it clear that realist explanations in quantum physics preclude the ability to predict successfully in that area. That is, realism does not only fail to explain the success of quantum physics but the appeal to it hinders that success. No doubt some may read Bohr "charitably" and try to find some form of realism behind his words; but I doubt that any amount of cleverness can twist those words to the point that they mean the opposite of what they clearly say: “(...) radiation in free space as well as isolated material particles are abstractions, their properties on the quantum theory being definable and observable only through their interaction with other systems" (Bohr, 1987, pp. 56-57). Indeed, for the reasons previously stated, such interactions entail "the necessity of a final renunciation of the classical idea of causality and a radical revision of our attitude towards the problem of physical reality" (Bohr, 1970, p. 132).

Evolutionary biology treats realism even more unkindly than history, for reasons that to some degree resemble Bohr's epistemology. The most basic perceptual and conceptual equipment of organisms depends, at least in part, on their biology. An amoeba's perception of its environment depends on an interaction between its biology and that environment. A bird's perceptions depend on a central nervous system that results from two kinds of histories: the history of its own ancestors as they coped with a long sequence of environments, and its own individual history which fine-tuned its central nervous system. Our modes of thought also depend to a significant extent on our brains: People with unusual brain structures conceive of the world differently from most of us, as we can easily appreciate, for example, in Judith Ford's research on the neuroscience of schizophrenia (Ford et al., 2012).

Other animals perceive the world through even more drastically different senses: vipers detect heat, bats navigate with sonar, and some fishes' main interactions with the world are based on electric fields. Electroreceptors are particularly interesting. They work by analyzing the distortions of the returning electric waves or pulses the fish sends out. The fish needs a sophisticated system to distinguish its own returning signals from those emitted by other fishes, particularly members of its own species, for the latter could be rivals or possible mates. Entire social and courtship rituals depend on the proper manipulation of the fields 
(e.g., turning them down in the presence of a friendly fish). The world appears very different to them than it does to us. We depend, for instance, on the perception of surfaces that reflect light, which to the fish may not be an important consideration (those surfaces may be transparent to the electroreceptor), while the changes in mood that are given away by changing electric fields may well be.

The important lesson, for my purposes in this paper, is that such different senses are likely to require different brain structures. As intelligence develops, it follows the paths open to it by the structures with which the animal interprets the world, including its social world, and which the animal uses to cope with that world. This is not a mere theoretical point. We can find examples of such differences in structure in Sensory Exotica, a very interesting work by Howard C. Hughes (1999). An intelligent creature whose main sensory modality is electric rather than visual would have patterns of thought completely foreign to us.

It is clear that different species may well (and sometimes do) experience the world differently. Those different ways of experiencing the world are relative to what we may call frames of reference (partially) determined by biology. It is as if the "world" were being measured in these different frames, and so it is not surprising that many different kinds of experiences are possible (as are ways of thinking about the "world").

It is obvious that some frames are better than others, at least for specific abilities. Some animals see much better than others, for example. And some, say humans, are much more capable of producing powerful sciences than most if not all others. Perhaps it is tempting to think, as in the realist assumption, that what makes one frame better than another is that it yields a more accurate representation of the truth, but biologically this makes little sense. A bird has a certain perceptual apparatus for the simple reason that it served its ancestors well enough. It succeeded, and because it did, it was passed on. Another species may be served just as well by a different perceptual apparatus, which will also be passed on because it has enabled (or at least allowed) that species to succeed. These frames are the product of natural history, and natural history is a long path of millions upon millions of contingencies. One more accident here, one less there, and a particular lineage could have gone in a completely different direction, perhaps extinct. Moreover, no matter how good a frame is, natural history could have brought about another that is just as good, although very different. Birds, bats, and bees all fly, even though the anatomical structures that enable them to do so are not only very different but incompatible. Humans and shrimp see in the same visual spectrum, but some shrimps see as many as 11 different primary colors, whereas we have three. If, as a matter of fact, there is no other frame that enables another species to succeed just as well, neither here nor in any other part of the universe, then that is one more accident. Natural history could have made it otherwise.

There might exist "brains" with structures as different from ours as a bat's flight mechanism is from those of birds and insects, but which nevertheless may serve those other species as well as our kind of brain serves our own species. Or they might enable them to perform even better (as science fiction constantly imagines). In either case it would be highly arbitrary to insist that whatever science our brains develop best resembles the God's Eye point of view. Human science at its best was supposed to "represent" the world as it really was, or at least to get closer and closer to such a representation -that is presumably why science was so successful. But the truth of such representation of the world depended on its being a unique representation. Thus, the realist has to hope that such possible alternative representations, developed within what we may call different biological frames of reference, are equivalent representations (either logically, conceptually, empirically, or theoretically, perhaps even mathematically, equivalent). Trying to show this, however, is an exceedingly tall order for the realist. The conceptual aspects of these other possible biological frames of reference may be even more beyond conceptualization by us than our ability to imagine the perceptual experience of fishes whose main sensory contact with the world around them comes from electric fields.

Nevertheless, the realist may wish to put the onus of the argument on me. How can I rule out a potential theory of invariants between the sciences developed within different biological frames of reference? Now, with the reader's indulgence, I would like to include a personal note at this point. This was the very objection that Paul Feyerabend wrote to me in a postcard when I was in my last 
year of doctoral studies. Carl Hempel was visiting at Berkeley that year, and I was his teaching assistant while Feyerabend was traveling. I had found the postcard in my mailbox right before one of Hempel's lectures and could not resist reading it during Hempel's terrific presentation. Nor could I resist writing my reply on the margins of the postcard (which I expanded in Ch. 3 of my Radical Knowledge and later publications). That reply is essentially this: Such a theory of invariants would be possible, if at all, within a cognitive (biological) frame of reference. There could be, therefore, some other, quite different, theories of invariants developed within alternative cognitive (biological) frames of reference. A meta-theory of invariants would suffer the same fate, as would a meta-meta-theory, and so on...

Thus, both the history of science (Galileo, Prout, Bohr, etc.) and evolutionary biology undermine realism. Realists being philosophers, though, cling to the hope that their impulse (their view "feels right") should gain some strength by default, given the serious objections against relativism, which presumably would also hold against evolutionary relativism.

The most famous objection is Plato's argument to the effect that the relativist's denial of an absolute truth entails that all points of view are equally valid. If so, however, absolutism is also valid. But absolutism implies that relativism is false. Therefore, if relativism is true, it is then false. This shows that relativism is incoherent. Nevertheless, Plato committed a logical mistake. The negation of the claim that there can be only one true view of the world does not entail that all points of view are equally valid: It only entails that there might be more than one valid point of view. Which is exactly what evolutionary relativism claims.

According to some philosophers, e.g. Tuomela (1985), the universe must be independent of any cognitive frames of reference. If it were not, then it would not come into existence until it could be described within the point of view of some observer or other, and it would go out of existence when there are no longer any observers to describe it. Presumably, this consequence reduces relativism to absurdity. But evolutionary relativism requires only potential frames of reference. Otherwise imagine arguing that the Special Theory of Relativity is absurd because it implies that, before there was anyone around to measure mass, objects had no mass!

Another favorite argument is that a relativist has to accept at least one truth: that relativism is true. Philosophers then conclude that at the meta-level relativism has to rely on an absolute truth. Thus absolutism (scientific realism at its ideal limit) triumphs after all. This is an instance of begging the question, though. When absolute truth is called into question, philosophers demand that any serious alternative must be offered as an absolute truth!

I personally accept evolutionary relativism as a relative truth, i.e. relative to our biological frame of reference. Within that frame of reference, it performs much better than the competition, for it explains science in a way that is consistent both with the history of science and evolutionary biology. As we have seen when two frames lead to similar performance, it is arbitrary to make either one a preferred frame, let alone an absolute one. This indicates that the notion of performance can be fruitfully tied to the notion of understanding, particularly to that of scientific understanding. Such a connection between performance and understanding underpins a biological theory of relative truth.

Human science is ultimately part of the human phenotype. Some phenotypic expressions exploit better the resources of our genotype in a given environment. Likewise, some scientific viewpoints (with their complex machinery of practices, experimental procedures, and so on) permit us to exploit better the resources of our genotype in a given environment (e.g., in dealing with the dynamics of bodies). In other words, some viewpoints enable us to realize more of our potential for performance. In this biological context, a viewpoint is said to be relatively true when it approaches the limits of the resources of the genotype. When a theory allows us to deal with the world in a great variety of ways, when thinking that the world is as the theory tells us leads to continuing success, when this capacity for performance clearly surpasses that of its competitors, then we come to think that the world must be so. And in a limited domain we may not be able to conceptualize the world any better. It is then that many scientists tend to speak of truth: it is hard for them to imagine, at that point, how the world could be otherwise. Though they have not "looked 
into the mind of God," this account explains why it may be worthwhile to make distinctions between true and untrue: a viewpoint is true because the interaction (with the world) that results is of great quality (or seems to be) and very superior to its alternatives.

Relative truth turns the tables on the realist: The relative truth (or seeming absolute truth) of a viewpoint depends on its success, not the other way around. When we see the world, we see it as something or other. Some of this "seeing as" holds us in a strong grip because it permits such a strong interaction with the world. It is that grip under those conditions of successful interaction that philosophers have been trying to explain with correspondence theories of truth. As I have argued in my Evolution and the Naked Truth, the relativistic ideal of truth is a changeable one. This may allow us to understand why scientists so often feel that they are pretty much in possession of the truth, while at the same time allowing that others who had similar feelings in the past were "wrong," and even that others in the future may dismiss ideas that seem perfectly obvious to us now. At times, we may come close to "truth" with respect to a certain environment, just as some species may come close to adaptation to a given environment: But as conditions change, other ideas will be more appropriate and thus come to be considered true.

\section{Conclusion.}

Although Kuhn made valuable contributions to the topic at issue, they do not directly touch on the points I have chosen to emphasize. They also involve all sorts of side controversies that I did not find quite relevant for my purposes. In any event, his main disagreement with Feyerabend was about the latter's insistence on the proliferation of theories and the role that proliferation plays on radical changes in science that bring about progress (as future generations so judge). On that point Galileo's arguments make it clear which side history favors. When you consider alternative views, you change theoretical assumptions, and as a result you also change what counts as evidence. Points all that Feyerabend elaborated in Against Method and most of his subsequent work.

I have argued that evolutionary biology undermines the analogy between the "evolution" of scientific ideas and the evolution of species, and that insofar as evolutionary biology gives us insights about the brain and the nature of science, it also undermines scientific realism, and consequently the support some hoped it would provide to the notion of the gradual or continuous growth of science. In the process, I have marshalled many resources from biology, particularly about perception and intelligence, to support evolutionary relativism; I have dealt with the most important objections to relativism; and, finally, I have provided a biologically-based theory of relative truth. I trust these proposals go beyond the well-known arguments of post-Kuhnian historicist philosophy of science. I hope the reader will find them worthy of consideration.

"Radical Knowledge" is not a mere "theoretical" thesis within the philosophy of science. It is intended rather as a description both of the history of science and of the sort of activity that we should expect from a social extension of intelligence to the exploration of nature. The knowledge that results is not "radical" merely in some abstract or theoretical sense. On the contrary, as we saw with Galileo and Prout, it describes not only theoretical changes in science but changes of the body of facts. Rocks do not fall vertically from towers, even thought our eyes tell us that they do. They fall in a parabolic motion. "Radical Knowledge" recognizes that very drastic changes may occur at any level of our scientific enterprise and that pursuing them may yield scientific progress.
Acknowledgments:

I thank David Paulsen for his valuable comments. 


\section{Referencias}

Aristotle. (1934). On the Heavens II, Ch. 14, 296b7-24. Cambridge, MA: Harvard University Press.

Barnes, E.C. (2002). The Miraculous Choice Argument for Realism. Philosophical Studies, 111(2), 97-120. doi:10.1023/A:1021204812809

Bohr, N. (1970). Can Quantum Mechanical Description be Complete? In S. Toulmin (Ed.), Physical reality: Philosophical essays on twentieth-century physics. New York: Harper \& Row.

Bohr, N. (1982). Discussion with Einstein on Epistemological Problems in Atomic Physics. In P. A. Schilpp (Ed.), The Library of Living Philosophers, Volume 7. Albert Einstein: PhilosopherScientist (pp. 199-241). Chicago, Illinois: Open Court.

Bohr, N. (1987). The Quantum Postulate and the Recent Development of Atomic Theory. In N. Bohr, The Philosophical writings of Neil's Bohr (Atomic Theory and the Description of Nature, Vol. 1). Connecticut, USA: Ox Bow Press.

Boyd, R. (1992). On the Current Status of Scientific Realism. In R. Boyd, P. Gasper, and J.D. Trout (Eds.), The Philosophy of Science (pp. 195-222). Cambridge, USA; MIT Press.

Brown, J. R. (1982). The Miracle of Science. Philosophical Quarterly, 32(128), 232-244. doi:10.2307/2219325

Busch, J. (2008). No New Miracles, Same Old Tricks. Theoria, 74(2), 102-114. doi:10.1111/j.1755-2567.2008.00011.x

Dellsén, F. (2016). Explanatory Rivals and the Ultimate Argument. Theoria, 82(3), 217-237. doi:10.1111/theo.12084

Edelman, G. \& Tononi, G. (2000). A Universe of Consciousness: How Matter Becomes Imagination. New York: Basic Books.

Feyerabend, P. (1975). Against Method: Outline of an Anarchist Theory of Knowledge. London: New Left Books.

Feyerabend, P. (1999). Conquest of Abundance: A Tale of Abstractness versus the Richness of Being. Chicago: University of Chicago Press.

Ford, J.M., Dierks, T., Fisher, D.J., Herrmann, C.S., Hubl, D., Kindler, J., Koenig, T., Mathalon, D.H., Spencer, K.M., Strik, W., \& van Lutterveld, E. (2012). Neurophysiological Studies of Auditory Verbal Hallucinations. Schizophrenia Bulletin, 38(4), pp. 715-723.

Frost-Arnold, G. (2010). The No-Miracles Argument for Realism: Inference to an Unacceptable Explanation. Philosophy of Science, 77(1), 35-58. doi:10.1086/650207

Galileo. (1989). The Assayer. In M.R. Matthews (Ed.), The Scientific Background to Modern Philosophy (pp. 56-61). Indianapolis, USA: Hackett.

Galileo. (2001). Dialogues Concerning the Two Chief World Systems. New York: The Modern Librar.

Hahlweg, K. \& Hooker, C.A. [Eds.]. (1989). Issues in Evolutionary Epistemology (Volume 3, No. 2). Albany, USA: SUNY Press.
Hughes, H. C. (1999). Sensory Exotica. Cambridge, USA: MIT Press.

Johnston, V. S. (1999). Why We Feel. New York, USA: Perseus Books.

Lakatos, I. (1970a). Methodology of Scientific Research Programmes. In I. Lakatos and A. Musgrave (Eds.), Criticism and the Growth of Knowledge. Cambridge, UK: Cambridge University Press.

Lakatos, I. (1970b). History of Science and its Rational Reconstructions. In R.C. Buck and R.S Cohen (Eds.), Boston Studies in the Philosophy of Science, Volume VIII (pp. 91-136). Dordrecht: Springer.

Lipton, P. (1994). Truth, Existence, and the Best Explanation. In A.A. Derksen (Ed.), The Scientific Realism of Rom Harré (pp. 89-111). Tilburg: Tilburg University Press.

Lyons, T. D. (2003). Explaining the Success of a Scientific Theory. Philosophy of Science, 70(5), 891-901. doi:10.1086/377375

Munevar, G. (1981). Radical Knowledge: A Philosophical Inquiry into the Nature and Limits of Science. UK: Avebury Publishing Co.; Indianapolis, USA: Hackett Publishing.

Munevar, G. (1989). Science as Part of Nature. In K. Hahlweg and C.A. Hooker (Eds.), Issues in Evolutionary Epistemology (Volume 3, No. 2). Albany, USA: SUNY Press.

Munevar, G. (1998). Evolution and the Naked Truth. Aldershot, UK: Ashgate Publishing Ltd.

Munevar, G. (2018). A Theory of Wonder (book manuscript in preparation).

Newton. (1989). Principia. In M.R. Matthews (Ed.), The Scientific Background to Modern Philosophy (pp. 137-153). Indianapolis, USA: Hackett Publishing Company.

Piaget, J. (1969). Psychology of Intelligence. New York, USA: Littlefield, Adams and Co.

Popper, K. (1972). Objective Knowledge. Oxford, UK: Oxford University Press.

Psillos, S. (1999). Scientific Realism: How Science Tracks Truth. London: Routledge.

Putnam, H. (1975). Mathematics, Matter and Method. Cambridge: Cambridge University Press.

Sarton, G. (1936). The Study of the History of Science. Cambridge, MA: Harvard University Press.

Toulmin, S. (1972). Human Understanding, Volume I. Princeton, USA: Princeton University Press.

Tuomela, R. (1985). Science, Action and Reality. Dordrecht, Holland: Reidel. 